\title{
CONSORCIAÇÃO DE BRAQUIÁRIAS COM MILHO OUTONAL EM PLANTIO DIRETO SOB PIVÔ CENTRAL ${ }^{1}$
}

\author{
CARLOS A. CHIODEROLI ${ }^{2}$, LUIZ M. M. DE MELLO ${ }^{3}$, PAOLA J. GRIGOLLI ${ }^{4}$, \\ JOSÉ O. DA R. SILVA ${ }^{5}$, ANDRÉ L. CESARIN ${ }^{6}$
}

\begin{abstract}
RESUMO: Em regiões de clima tropical, com altas taxas de decomposição do material orgânico, uma alternativa para suprir o aporte anual de palha exigido para proporcionar a sustentabilidade do sistema plantio direto é a consorciação de forrageiras com culturas produtoras de grãos. Com o objetivo de identificar, no sistema de integração agricultura-pecuária, a melhor modalidade de consorciação de três espécies de braquiária (Brachiaria brizantha B. decumbens, e B. ruzizienses) com milho outonal (linha, entrelinha e entrelinha na época de adubação de cobertura do milho), foi conduzido o presente trabalho. Foi utilizado o delineamento em blocos ao acaso, no esquema fatorial (3x3), com quatro repetições. Foram avaliadas: massa seca de palha do milho, massa seca da palha de braquiária, massa seca total de palha, massa de 1.000 grãos e produtividade de grãos. Os resultados demonstraram que, quando o foco principal da consorciação de milho com braquiária for produtividade de grãos e o foco secundário for formação de palha, a utilização da Brachiaria ruzizienses semeada na época de adubação de cobertura do milho proporcionou maiores valores de produtividade de grãos. Todos os tratamentos produziram quantidade de palha suficiente para a manutenção da estabilidade do sistema de semeadura direta.
\end{abstract}

PALAVRAS-CHAVE: cobertura do solo, integração lavoura-pecuária, palhada, sucessão de culturas, Brachiaria.

\section{CONSORTIUM OF PASTURE WITH FALL CORN IN NO TILLAGE UNDER CENTER PIVOT}

\begin{abstract}
In tropical regions with high rates of organic material decomposition, an alternative to supply the annual amount of straw required to provide the no tillage system sustainability is the use of intercrop of forage plants with grain crop. The present work was conducted with the objective of identify the best intercrop modality of three species of brachiaria (Brachiaria brizantha, $B$. decumbens and $B$. ruziziensis) with fall maize (row, interrow, interrow at the moment of maize coverage fertilization) in the pasture-agriculture integration system. It was used a randomized block design in a factorial scheme $(3 \times 3)$ with four repetitions evaluating dry weight of maize straw, dry matter of pasture straw, total dry weight of straw, 1000 grain weight and grain yield. The results showed that when the main focus of intercropping maize with pasture for grain yield and the secondary focus is the formation of straw, the use of Brachiaria ruziziensis sown at the time of maize manuring led to the highest grain yield. All treatments produced sufficient quantity of straw to maintain the stability of no tillage.
\end{abstract}

KEYWORDS: covering of the soil, agriculture-pasture integration, straw, succession of crops, Brachiaria.

\footnotetext{
${ }^{1}$ Extraído da dissertação de Mestrado do primeiro autor.

${ }^{2}$ Eng ${ }^{0}$ Agrônomo, Doutorando do Programa de Pós-Graduação em Ciência do Solo, Faculdade de Ciências Agrárias e Veterinárias (FCAV/UNESP), Departamento de Engenharia Rural (LAMMA), Jaboticabal - SP, ca.chioderoli@uol.com.br.

${ }^{3}$ Eng ${ }^{0}$ Agrônomo, Professor Adjunto, Departamento de Fitossanidade, Engenharia Rural e Solos, Faculdade de Engenharia/UNESP, Ilha Solteira - SP.

${ }^{4}$ Graduanda do Departamento de Fitossanidade, Engenharia Rural e Solos, Faculdade de Engenharia, UNESP, Ilha Solteira - SP.

${ }^{5}$ Graduando do Departamento de Fitossanidade, Engenharia Rural e Solos, Faculdade de Engenharia, UNESP, Ilha Solteira - SP.

${ }^{6}$ Graduando do Departamento de Fitossanidade, Engenharia Rural e Solos, Faculdade de Engenharia, UNESP, Ilha Solteira - SP.

Recebido pelo Conselho Editorial em: 12-3-2010

Aprovado pelo Conselho Editorial em: 5-10-2010
} 


\section{INTRODUÇÃO}

A prática da consorciação de culturas produtoras de grãos com forrageiras tropicais, na safra de verão, está sendo utilizada por técnicos e agricultores com intuito de antecipar a implantação da forrageira, principalmente em regiões onde o inverno é seco e não permite bom desenvolvimento de culturas de safrinha. Esse método permite a utilização das forrageiras, tanto para a produção de palhada como para a instalação da pastagem.

No sistema de integração agricultura-pecuária, a produção de culturas de grãos, especialmente o milho, sorgo e arroz, consorciadas com forrageiras tropicais, principalmente as do gênero Brachiaria, é conhecida como Sistema Santa Fé (CUNHA et al., 2007), no qual a forrageira pode ter dupla finalidade: servindo para a exploração pecuária, a partir do final do verão até início da primavera, e, posteriormente, para formação de palha para a manutenção do sistema plantio direto (SPD).

Segundo MELLO et al. (2004), esse sistema integra as duas atividades com os objetivos de maximizar racionalmente o uso da terra, diversificar e verticalizar a produção, minimizar custos e agregar valores aos produtos, através do aproveitamento dos recursos e benefícios que uma atividade proporciona à outra. Porém, por tratar-se de um sistema novo, existem questionamentos em relação à compactação do solo, efeitos nas culturas posteriores e sobre a quantidade de resíduos de palha para a cobertura do solo.

O SPD e a integração agricultura-pecuária são alternativas de manejo que conciliam a manutenção e até mesmo a elevação da produção, com maior racionalidade dos insumos empregados (SANTOS et al., 2008). Além disto, ocorre o aumento da matéria orgânica que incrementa a qualidade do solo (CONCEIÇÃO et al., 2005), promovendo a agregação, com reflexos positivos na partição da água, favorecendo a infiltração e diminuindo o escoamento superficial.

Portanto, para manter anualmente o aporte de palha exigido para a manutenção da estabilidade do SPD, é de fundamental importância o estabelecimento de culturas para a produção de palha, em quantidade adequada à cobertura do solo, e que minimize o acelerado processo de decomposição da mesma. Assim, deve-se conhecer a espécie vegetal a ser utilizada no programa de rotação ou consorciação de culturas, quanto à sua produção de massa seca e tempo de decomposição, que interferem diretamente na quantidade de palha sobre $\mathrm{o}$ solo e, consequentemente, nos atributos químicos do solo, dentre os quais a CTC, que afetam diretamente a dinâmica de cátions no solo (ANDREOTTI et al., 2008).

Espécies forrageiras perenes, como Brachiaria decumbens, B. brizantha, Panicum maximum cv. Tanzânia e $P$. maximum cv. Mombaça, além de fornecerem grande quantidade de massa seca, que é fundamental para o SPD, apresentam alta relação carbono/nitrogênio $(\mathrm{C} / \mathrm{N})$, retardando a velocidade de decomposição da palha, aumentando a possibilidade de utilização em regiões mais quentes na proteção do solo por mais tempo contra erosão e radiação (TIMOSSI et al., 2007). As espécies do gênero Brachiaria, de maneira geral, vêm sendo consideradas opções proeminentes na formação da palhada para o SDP, devido à boa produção de massa seca e à alta relação $\mathrm{C} / \mathrm{N}$ de sua composição (NUNES et al., 2006).

Tal sistema tem sido estudado por vários pesquisadores (FREITAS et al., 2005; JAKELAITIS et al., 2005; JAKELAITIS et al., 2006), os quais relataram que, na maioria dos estudos, a presença da forrageira não afetou a produtividade de grãos de milho. Portanto, o consórcio, quando praticado de maneira tecnicamente correta, proporciona o aumento da quantidade de palha, visando à melhor cobertura do solo para a realização da semeadura direta e, muitas vezes, o aumento de produtividade na cultura sequente e/ou a antecipação da formação de pastagem.

Assim, o objetivo do presente trabalho foi identificar a melhor época e modalidade de semeadura de três espécies de braquiárias em consórcio com o milho de outono, com ênfase para a produtividade do milho e formação de palha para o sistema de semeadura direta. 


\section{MATERIAL E MÉTODOS}

O experimento foi conduzido no outono de 2008, na Fazenda de Ensino, Pesquisa e Extensão da Faculdade de Engenharia - UNESP - Ilha Solteira, situada no município de Selvíria - MS, nas coordenadas geográficas $51^{\circ} 24^{\prime} \mathrm{W}$ e $20^{\circ} 20^{\prime} \mathrm{S}$, com altitude de $350 \mathrm{~m}$. O solo da área experimental foi classificado como Latossolo Vermelho distroférrico, textura argilosa (EMBRAPA, 2006), com declive médio de $4 \%$ e boa drenagem. O clima, de acordo com a classificação de Köeppen, é Aw, subtropical úmido, com estiagem no período do inverno. $\mathrm{O}$ fornecimento de água foi realizado pelo sistema de irrigação Pivô Central, seguindo o manejo de rotina da fazenda.

A área experimental estava conduzida em SPD há 8 anos e apresentava como cultura antecessora a soja. Utilizou-se o delineamento em blocos ao acaso, com nove tratamentos, em esquema fatorial $3 \times 3$, com quatro repetições. As parcelas experimentais foram constituídas por oito fileiras de milho, espaçadas entre si por $0,90 \mathrm{~m}$, com $23 \mathrm{~m}$ de comprimento. Os tratamentos foram formados por três espécies de braquiárias: (Brachiaria brizantha, B. decumbens e B. ruzizienses) e três modalidades de consórcio de braquiárias com milho: milho com braquiária na linha de semeadura, misturada ao adubo de base do milho; milho com braquiária semeada na entrelinha com adubador de cobertura para plantio direto no mesmo dia da semeadura do milho, com a presença de uma linha de semeadura intermediária e braquiária na entrelinha do milho semeada junto com o adubo de cobertura do milho, no estádio $\mathrm{V}_{4}$.

Foram utilizados os equipamentos agrícolas: trator de pneus (4x2 TDA), com potência máxima de 77,28 kW no motor; trator de pneus (4x2), com potência máxima de $54,4 \mathrm{~kW}$ no motor; pulverizador de acoplamento ao engate de três pontos do sistema hidráulico, com barra de $12 \mathrm{~m}$ de comprimento, provida de 24 pontas do tipo leque $110-02$, espaçadas entre si por $0,50 \mathrm{~m}$ e tanque com capacidade de $600 \mathrm{~L}$ de calda; adubador de cobertura para plantio direto, com largura de chassi 2,30 m e 4 discos de corte duplos desencontrados de diâmetro EM MM (13"x 15") e 2 depósitos com capacidade de 220 L; semeadora-adubadora de arrasto, com sistema pneumático de dosagem de sementes, configurada para semeadura direta com disco de corte frontal, sulcador de haste para deposição do adubo e discos duplos desencontrados para deposição de sementes, rodas controladoras de profundidade paralelas e rodas compactadoras em "V".

Foi utilizado o híbrido simples precoce de marca comercial DKB 390, com densidade de semeadura de 5,4 sementes $\mathrm{m}^{-1}$, semeado no dia 13-5-2008. Na consorciação, foram utilizados $18 \mathrm{~kg} \mathrm{ha}^{-1}$ de sementes certificadas de Brachiaria brizantha cv. Marandu, Brachiaria decumbens e Brachiaria ruzizienses com valor cultural de 32\%. Para adubação de base do milho, foram utilizados $300 \mathrm{~kg} \mathrm{ha}^{-1}$ da fórmula comercial 08-28-16 e, na adubação de cobertura, com o milho no estádio $\mathrm{V}_{4}$, foram aplicados $120 \mathrm{~kg} \mathrm{ha}^{-1}$ de cloreto de potássio e $300 \mathrm{~kg} \mathrm{ha}^{-1}$ de ureia. As sementes de milho foram tratadas com tiodicarbe, na dose de $600 \mathrm{~g}$ do ingrediente ativo (i.a) para $100 \mathrm{~kg}$ de sementes. Antes da semeadura do milho, no dia 2-5-2008 foi realizada a dessecação das plantas daninhas presentes na área experimental com glifosato $\left(2,160 \mathrm{~kg} \mathrm{ha}^{-1}\right)$ em área total.

Dois dias após a semeadura do milho, foi realizada aplicação de herbicida dessecante de contato (paraquat a 0,240 kg i.a. ha ${ }^{-1}$ ), com volume de aplicação de $200 \mathrm{~L} \mathrm{ha}^{-1}$, com a finalidade de eliminar as plântulas que emergiram após a dessecação. Antes da adubação de cobertura do milho, foi aplicada atrazina (1 kg i.a. ha ${ }^{-1}$ ). Para controle de lagartas-do-cartucho (Spodoptera frugiperda), foi utilizado o lufenurom ( $15 \mathrm{~g}$ i.a. $\left.\mathrm{ha}^{-1}\right)$. As colheitas do milho e da massa seca das braquiárias foram realizadas no dia 20-10-2008. A massa seca de braquiária foi avaliada por quatro subamostras por parcela, coletadas por meio de uma armação de ferro com área de $0,25 \mathrm{~m}^{2}$, nas entrelinhas do milho, nos tratamentos nos quais as forrageiras foram semeadas nas entre linhas e para as forrageiras semeadas na linha, coletaram-se $2 \mathrm{~m}$ de duas fileiras da área útil da parcela. $\mathrm{O}$ material colhido foi pesado e uma amostra foi levada à estufa com circulação forçada de ar, por $72 \mathrm{~h}$ e a $65^{\circ} \mathrm{C}$, determinando-se a massa seca e, posteriormente, calculada a produção de massa seca $h^{-1}$. Para a avaliação da produção de grãos e palha do milho, foram colhidas as plantas da área útil de cada parcela (4 linhas de 5,0 m) e submetidas à trilha mecânica. Os grãos foram separados, 
pesados e os valores corrigidos para a base úmida de 13\%. Dos grãos colhidos, foram separadas oito amostras por parcela para a determinação da massa de 1.000 grãos, na base úmida de $13 \%$.

Os dados foram submetidos à análise de variância e, quando o valor do teste $\mathrm{F}$ foi significativo a, pelo menos, $10 \%$ de probabilidade, realizou-se o teste de Tukey, a $10 \%$ de probabilidade para a comparação de médias, com o auxílio do programa computacional estatístico SISVAR (FERREIRA, 1999).

\section{RESULTADOS E DISCUSSÃO}

Verifica-se que a massa de 1.000 grãos e a produtividade de grãos de milho foram influenciadas significativamente pelas espécies de forrageiras, com maiores valores obtidos no tratamento em que se utilizou $B$. ruzizienses, e os menores foram observados no tratamento com $B$. brizantha (Tabela1).

TABELA 1. Valores médios de massa de 1.000 grãos e produção de grãos de milho no sistema de consorciação de braquiárias com milho, em diferentes modalidades de semeadura. .

Mean values of weight of 1000 grains and grain yield of maize in intercropping system with Brachiaria under different methods of sowing.

\begin{tabular}{cccc}
\hline \multicolumn{2}{c}{ Causas de Variação } & Massa de 1.000 grãos $(\mathrm{kg})$ & ${\text { Produtividade de grãos }\left(\mathrm{kg} \mathrm{ha}^{-1}\right)}^{2}$ \\
\hline \multirow{2}{*}{ Forrageiras } & B. brizantha & $0,349 \mathrm{~b}$ & $7,811 \mathrm{~b}$ \\
$(\mathrm{~F})$ & B. decumbens & $0,353 \mathrm{ab}$ & $8,098 \mathrm{ab}$ \\
& B. ruzizienses & $0,364 \mathrm{a}$ & $8,461 \mathrm{a}$ \\
\hline Modalidades & Linha & $0,341 \mathrm{~b}$ & $7,514 \mathrm{c}$ \\
Semeaduras & Entrelinha & $0,354 \mathrm{ab}$ & $8,124 \mathrm{~b}$ \\
$(\mathrm{M})$ & Cobertura & $0,365 \mathrm{a}$ & $8,733 \mathrm{a}$ \\
\hline \multirow{2}{*}{ Valor de F } & $\mathrm{F}$ & $3,712^{*}$ & $2,669^{*}$ \\
& $\mathrm{M}$ & $3,415^{*}$ & $9,348^{*}$ \\
\hline C.V. $(\%)$ & F X M & 0,400 & 1,325 \\
\hline DMS & & 3,97 & 8,50 \\
\hline
\end{tabular}

Médias seguidas de mesma letra na coluna não diferem pelo teste de Tukey, a $10 \%$ de probabilidade

Esses resultados indicam que $B$. brizantha exerceu maior interferência na cultura do milho quando comparada com B. ruzizienses. De acordo com FANCELLI \& DOURADO NETO (2000), o potencial produtivo do milho é definido precocemente, ou seja, por ocasião da emissão da $4^{\mathrm{a}}$ folha, podendo estender-se até a $6^{\mathrm{a}}$ folha, principalmente em função da diferenciação da inflorescência masculina antes da inflorescência feminina. A massa de 1.000 grãos é um importante componente da produtividade de grãos, podendo ser afetada por qualquer tipo de estresse que a planta sofra após o florescimento. Contudo, é importante ressaltar que as características que estão relacionadas com a produtividade de grãos podem ser afetadas por qualquer tipo de estresse da planta nessas fases.

Conforme PIRES (2006), dentre as três espécies de Brachiaria em estudo, a B. decumbens é a que apresenta menor potencial de produção de massa seca, principalmente pelo seu hábito de crescimento decumbente e alta relação caule/folha ${ }^{-1}$ ao atingir a maturidade fisiológica. Com relação à $B$. ruziziensis, esta espécie pode ser recomendada para sistemas de integração lavoura-pecuária, visto que, apesar de menor produção de massa seca que a B. brizantha, de acordo com PIRES (2006) e CECCON (2007), pode proporcionar rápida cobertura do solo, boa composição bromatológica, excelente reciclagem de nutrientes, facilidades em sua dessecação e produção uniforme de sementes.

Com relação às modalidades de semeadura, as forrageiras semeadas na linha do milho promoveram maior interferência com a cultura principal, refletindo em menores produtividades. As 
braquiárias semeadas na época da adubação de cobertura do milho proporcionaram maiores valores de massa de 1.000 grãos, sendo estatisticamente significativos.

Para a produtividade de grãos, verifica-se que tanto para a variável forrageira, como para a modalidade de semeadura, houve efeito significativo. B. ruzizienses proporcionou maiores valores de produtividade de grãos, diferindo significativamente da $B$. brizantha, que apresentou menores valores, dada a maior interferência com o milho, independentemente da modalidade de semeadura utilizada.

Esses resultados corroboram os obtidos por MELLO et al. (2007), que, trabalhando com consórcio de $B$. brizantha e milho, na mesma região e tipo de solo, detectaram a interferência exercida pela forrageira sobre o milho, quando consorciada na linha de semeadura e a lanço em área total, no mesmo dia da semeadura do milho. Os resultados mostram que essas modalidades de consórcio afetaram o desenvolvimento do milho, reduzindo a produção de grãos, quando comparados com a produção obtida no tratamento de milho solteiro.

Resultados semelhantes foram obtidos por PANTANO (2003), que, trabalhando com consórcio de braquiária com milho, na mesma região e mesmo solo deste trabalho, detectou a interferência exercida pela $B$. brizantha sobre o milho, quando consorciada na linha de semeadura, relatando que essa modalidade de consórcio afetou o desenvolvimento do milho, reduzindo a produção de grãos.

No consórcio efetuado na época de cobertura, a competitividade é menor porque o milho ultrapassa o período crítico de interferência (PCPI), que corresponde a um período de nove dias após emergência, ou seja, estádio fenológico $V_{2}$ (duas folhas expandidas), período em que a cultura pode conviver com as plantas daninhas sem que ocorra redução significativa em sua produtividade (KOZLOWSKI et al., 2009).

Portanto, os resultados mostram que a modalidade de consórcio na qual as braquiárias são semeadas no mesmo dia do milho, principalmente na linha, existe a interferência no desenvolvimento inicial da cultura em virtude de estar dentro do período crítico de prevenção à interferência, impedindo a cultura principal de manifestar todo seu potencial produtivo.

Os valores de produtividade de grãos de milho consorciado com B. ruzzienses são semelhantes aos obtidos por CECCON (2007), e este consórcio promoveu maior produtividade de grãos que o milho consorciado com B. brizantha. Além disto, B. ruzizienses promove maior disponibilidade de palha após a colheita do milho e facilidade de manejo na dessecação para a implantação da cultura sequente.

A menor produtividade foi encontrada no tratamento com semeadura das forrageiras junto com o adubo de base do milho, demonstrando que essa modalidade proporcionou interferência da forrageira na cultura principal. Resultados mostrados por BORGHI \& CRUSCIOL (2007) afirmam que a consorciação de milho com braquiária promoveu, em média, menores produtividades de grãos de milho, concordando com os resultados obtidos neste trabalho, que mostra a interferência exercida pelas forrageiras, principalmente pela $B$. brizantha.

A produção de massa seca de palha do milho mostrou comportamento inverso na produtividade de grãos. Os maiores valores foram obtidos com as forrageiras semeadas na linha, diferindo significativamente do tratamento no qual se utilizaram as forrageiras semeadas na adubação de cobertura do milho, mas não apresentando diferença estatística significativa quando semeadas na entrelinha no mesmo dia da semeadura do milho (Tabela 2). 
TABELA 2. Valores médios de massa seca de palha do milho $\left(\mathrm{kg} \mathrm{ha}^{-1}\right)$, massa seca da palha de braquiária $\left(\mathrm{kg} \mathrm{ha}^{-1}\right)$ e massa seca total de palha $\left(\mathrm{kg} \mathrm{ha}^{-1}\right)$ no sistema de consorciação de braquiárias com milho, em diferentes modalidades de semeadura. Mean values of dry corn straw $\left(\mathrm{kg} \mathrm{ha}^{-1}\right)$, dry grass straw $\left(\mathrm{kg} \mathrm{ha}^{-1}\right)$ and total dry mass of straw $\left(\mathrm{kg} \mathrm{ha}^{-1}\right)$ in the intercropped system of Brachiaria with maize in different sowing methods.

\begin{tabular}{ccccc}
\hline \multicolumn{2}{c}{ Causas de Variação } & $\begin{array}{c}\text { Massa Seca de Palha } \\
\text { do Milho } \\
\left(\mathrm{kg} \mathrm{ha}^{-1}\right)\end{array}$ & $\begin{array}{c}\text { Massa Seca } \\
\text { Braquiária } \\
\left(\mathrm{kg} \mathrm{ha}^{-1}\right)\end{array}$ & $\begin{array}{c}\text { Massa Seca Total de } \\
\text { Palha } \\
\left(\mathrm{kg} \mathrm{ha}^{-1}\right)\end{array}$ \\
\hline \multirow{2}{*}{ Forrageiras (F) } & B. brizantha & 9,143 & 2,651 & 11,794 \\
& B. decumbens & 9,652 & 2,422 & 12,074 \\
B. ruzizienses & 9,031 & 2,513 & 11,544 \\
Modalidades & Linha & $10,251 \mathrm{a}$ & $1,509 \mathrm{~b}$ & $11,760 \mathrm{ab}$ \\
Semeaduras (M) & Entrelinha & $9,166 \mathrm{ab}$ & $3,831 \mathrm{a}$ & $12,997 \mathrm{a}$ \\
& Cobertura & $8,408 \mathrm{~b}$ & $2,247 \mathrm{~b}$ & $10,655 \mathrm{~b}$ \\
\hline \multirow{2}{*}{ Valor de F } & $\mathrm{F}$ & 0,68 & 0,15 & 0,32 \\
& $\mathrm{M}$ & $5,33^{*}$ & $15,42^{* *}$ & $6,19 *$ \\
\hline CV $(\%)$ & $\mathrm{F} \times \mathrm{M}$ & 0,61 & 0,30 & 0,72 \\
\hline DMS & & 15,00 & 41,40 & 13,22 \\
\hline
\end{tabular}

Médias seguidas de mesma letra na coluna não diferem, pelo teste de Tukey, a 10\% de probabilidade.

Essa ocorrência pode ser devido à maior interferência das forrageiras consorciadas na linha com maior necessidade de luz solar para realização de fotossíntese e superação das condições adversas. Com isso, a cultura cresce com maior intensidade, refletindo proporcionalmente na produtividade de palha. O mesmo comportamento é relatado por SILVA et al. (2004), que explicam essa ocorrência devido à maior capacidade competitiva do milho em relação às espécies forrageiras, tendo maior desenvolvimento inicial e, consequentemente, melhor aproveitamento dos recursos em comum. Neste experimento, essa superioridade da cultura principal não refletiu na produtividade de grãos.

Em relação à produtividade de massa seca das forrageiras, as diferenças significativas ocorreram somente em função das modalidades de semeadura, não apresentando efeito significativo para as espécies de forrageiras (Tabela 2). As forrageiras semeadas na entrelinha, no dia da semeadura do milho, obtiveram maiores produtividades de massa seca, valores considerados significativos, pelo teste de Tukey, a $10 \%$ de probabilidade. As forrageiras semeadas na época de adubação de cobertura também sofreram o efeito de sombreamento do milho já estabelecido $\left(\mathrm{V}_{4}\right)$ e que também refletiu em maior produtividade de grãos de milho.

Os dados oriundos deste trabalho discordam de JAKELAITIS et al. (2005), que comentam que sistemas de semeadura de $B$. brizantha solteira ou em linhas e a lanço em consórcio com o milho, influenciaram fortemente na produção de forragem, mas não afetaram a produção de grãos de milho. Semeando B. ruziziensis na entrelinha do milho safrinha, no mesmo dia da semeadura, a produção do milho não foi afetada significativamente pela espécie em consórcio e, juntos, proporcionaram maior quantidade de resíduos vegetais que o milho solteiro (CECCON et al., 2005). Os mesmos autores destacaram também que os consórcios de milho safrinha com $B$. brizantha cv. Marandu B. decumbens. B. ruziziensis. e Pannicum maximum cv. Tanzânia, proporcionaram também maiores quantidades de nutrientes para ciclagem.

A produtividade de massa seca de palha total (milho + braquiárias) não apresentou diferenças significativas entre as espécies forrageiras (Tabela 2), porém, em relação às modalidades de semeadura, ocorreu diferença estatística significativa, sendo que o consórcio de milho + forrageira na entrelinha foi o que promoveu maior produtividade de massa seca de palha total, quando comparado com valores obtidos no consórcio de milho com braquiária semeada na época de 
adubação de cobertura. Os dados mostram que o milho consorciado com as forrageiras, na entrelinha, tem menor produtividade de massa seca de palha, mas é compensado pela maior quantidade de massa seca produzida pelas forrageiras, proporcionando maior cobertura do solo, sendo fundamental para a manutenção e longevidade do sistema plantio direto.

A quantidade acumulada de massa seca de palha, independentemente da espécie forrageira e da modalidade de consórcio, foi suficiente para suprir a quantidade de palha que deve ser adicionada anualmente à superfície do solo. Essas condições são fundamentais para que a semeadura direta tenha plenas condições de manifestar seu potencial como sistema sustentável. Esse aporte anual de resíduos, segundo LOVATO et al. (2004) e NICOLOSO et al.(2006), nas condições climáticas do Rio Grande do Sul, deve ser superior a $8 \mathrm{t} \mathrm{ha}^{-1}$ de massa seca de resíduos vegetais para que sejam mantidos estáveis os teores de matéria orgânica do solo. Portanto, para as regiões tropicais, com precipitações elevadas e altas temperaturas, o aporte anual de palha deve ser maior que nas regiões com condições climáticas semelhantes às do Rio Grande do Sul, preferencialmente com a utilização de culturas em sistema rotacionado (integração agriculturapecuária) e que proporcione maior longevidade de cobertura do solo com a palhada, com os valores semelhantes aos obtidos neste trabalho. Conforme BAYER (1996) \& FIORIN (1999), citados por AMADO (2000), o aporte anual de palha para o plantio direto, na região de cerrado, deve ser de 10 a $12 \mathrm{t} \mathrm{ha}^{-1}$.

Vale ressaltar também a importância de se avaliar o sistema como um todo, com um planejamento de sucessão/rotação de culturas adequado para garantir a sustentabilidade do SPD e integrar sistemas que envolvam lavoura e pecuária (PARIZ et al., 2009). Conforme ALLEN et al. (2007) e FRANZLUEBBERS (2007), os resultados desse sistema refletem os avanços nos aspectos de tecnologia, gestão, produtividade e incremento de lucratividade. De acordo com SULC \& TRACY (2007) e MAUGHAN et al. (2009), ainda há necessidade de financiamentos para novas pesquisas com o intuito de abordar melhor as consequências da integração agricultura-pecuária no complexo socioeconômico-ambiental.

\section{CONCLUSÕES}

Quando o foco principal da consorciação de milho com braquiária for produtividade de grãos e o foco secundário for formação de palha, a utilização da Brachiaria ruzizienses semeada na época de adubação de cobertura do milho proporcionou maiores valores de produtividade de grãos.

Todos os tratamentos produziram, para a região do cerrado, quantidade de palha suficiente para a manutenção da estabilidade da semeadura direta.

\section{AGRADECIMENTOS}

À Fundação de Amparo à Pesquisa do Estado de São Paulo (FAPESP), pelo apoio financeiro ao projeto.

\section{REFERÊNCIAS}

ALLEN, V.G.; BAKER, M.T.; SEGARRA, E.; BROWN, C.P. Integrated irrigated crop-livestock systems in dry climates. Agronomy Journal, Madison, v.99, n.2, p.346-360, 2007.

AMADO, T.J. Manejo da palha, dinâmica da matéria orgânica e ciclagem de nutrientes em plantio direto. In: ENCONTRO NACIONAL DE PLANTIO DIRETO NA PALHA, 7., 2000, Foz do Iguaçu. Resumos... Foz do Iguaçu: Federação Brasileira de Plantio Direto na Palha, 2000. p.105111.

ANDREOTTI, M.; ARALDI, M.; GUIMARÃES, V.F.; JUNIOR, E.F.; BUZETTI, S.

Produtividade do milho safrinha e modificações químicas de um latossolo em sistema plantio direto em função de espécies de cobertura após calagem superficial. Acta Scientiarum Agronomy, Maringá, v.30, n.1, p.109-115, 2008. 
BORGHI, E.; CRUSCIOL, C.A.C. Produtividade de milho, espaçamento e modalidade de consorciação com Brachiaria brizantha no sistema plantio direto. Pesquisa Agropecuária Brasileira, Brasília, v.42, n.2, p.163-171, 2007.

CECCON, G. Milho safrinha com solo protegido e retorno econômico em Mato Grosso do Sul. Revista Plantio Direto, Passo Fundo, v.16, n.97, p.17-20, 2007.

CECCON, G.; SAGRILO, E.; FERNANDES, F.M.; MACHADO, L.A.Z.; STAUT, L.A.; PEREIRA, M.G.; BACKES, C.F.; ASSIS, P.G.G.; SOUZA, G.A. Milho safrinha em consórcio com alternativas de outono-inverno para produção de palha e grãos, em Mato Grosso do Sul, em 2005. In: SEMINÁRIO NACIONAL DE MILHO SAFRINHA, 8., 2005, Assis. Resumos... Campinas: Instituto Agronômico, 2005. p.361-366.

CONCEIÇÃO, P.C.; AMADO, T.J.C.; MIELNICZUK, J.; SPAGNOLLO, E. Qualidade do solo em sistemas de manejo avaliada pela dinâmica da matéria orgânica e atributos relacionados. Revista Brasileira de Ciência do Solo, Viçosa-MG, v.29, n.5, p.777-788, 2005.

CUNHA, E.Q.; BALBINO, L.; STONE, L.; LEANDRO, W.; OLIVEIRA, G. Influência de rotações de culturas nas propriedades físico-hídricas de um Latossolo Vermelho em plantio direto.

Engenharia Agrícola, Jaboticabal, v.27, n.3, p.675-682, 2007.

EMBRAPA .EMPRESA BRASILEIRA DE PESQUISA AGROPECUÁRIA. Sistema brasileiro de classificação dos solos. 2.ed. Rio de Janeiro: CNPS, 2006. 306 p.

FANCELLI, A.L.; DOURADO-NETO, D. Produção de milho. Guaíba: Agropecuária, 2000. 360 p.

FERREIRA, D. F. SISVAR: Sistema de análise de variância. Lavras: UFLA/DEX, 1999.

FRANZLUEBBERS, A.J. Integrated crop-livestock systems in the Southeastern USA. Agronomy Journal, Madison, v.99, n.2, p.361-372, 2007.

FREITAS, F.C.L.; FERREIRA, F.A.; FERREIRA, L.R. Cultivo consorciado de milho para silagem com Brachiaria brizantha no sistema de plantio convencional. Planta Daninha, Viçosa-MG, v.23, n.4, p.635-644, 2005.

JAKELAITIS, A.; SILVA, A.F.; SILVA, A.A.; FERREIRA, L R.; FREITAS, F.C.L; VIANA, R.G. Influência de herbicidas e de sistemas de semeadura de Brachiaria brizantha consorciada com milho. Planta Daninha, Viçosa-MG, v.23, n.1, p.59-67, 2005.

JAKELAITIS, A.; SILVA, A.A.; SILVA, A.F.; SILVA, L. L.; FERREIRA, L.R.; VIVIAN, R. Efeitos de herbicidas no controle de plantas daninhas, crescimento e produção de milho e Brachiaria brizantha em consórcio. Pesquisa Agropecuária Tropical, Goiânia, v.36, n.1, p.53-60, 2006.

KOZLOWSKI, L.A.; KOEHLER, H.S.; PITELLI, R.A. Épocas e extensões do período de convivência das plantas daninhas interferindo na produtividade da cultura do milho (Zea mays). Planta Daninha, Viçosa-MG, v.27, n.3, p.481-490, 2009.

LOVATO, T.; MIELNICZUK, J.; BATYER, C.; VEZZANI, F. Adição de carbono e nitrogênio e sua relação com os estoques no solo com o rendimento do milho em sistemas de manejo. Revista Brasileira de Ciência do Solo, Viçosa-MG, v.28, n.1, p.175-187, 2004.

MAUGHAN, M.; FLORES, J.P.C.; ANGHINONI, I.; BOLLERO, G.; FERNÁNDEZ, F.G.; TRACY, B.F. Soil Quality and Corn Yield under Crop-Livestock Integration in Illinois. Agronomy journal, Madison, v.101, n.6, p.1.503-1.510, 2009.

MELLO, L.M.M.; PANTANO, A.C.; NARIMATSU, K.C.P. Integração agricultura-pecuária em plantio direto: consorciação braquiária e milho. In: CONGRESSO BRASILEIRO DE ENGENHARIA AGRÍCOLA, 36., 2007, Bonito. Anais... Jaboticabal: Associação Brasileira de Engenharia Agrícola, 2007. 1 CD-ROM. 
MELLO, L.M.M.; YANO, E.H.; NARIMATSU, K.C.P.; TAKAHASHI, C.M.; BORGHI, E. Integração agricultura-pecuária em plantio direto: produção de forragem e resíduo de palha após pastejo. Engenharia Agrícola, Jaboticabal, v.24, n.1, p.121-129, 2004.

NICOLOSO, R.S.; LANZANOVA, M.E.; LOVATO, T. Manejo das pastagens de inverno e potencial produtivo de sistemas de integração lavoura-pecuária no Estado do Rio Grande do Sul. Ciência Rural, Santa Maria, v.36, n.6, p.1.799-1.805, 2006.

NUNES, U.R.; JÚNIOR, V.C.A.; SILVA, E.B.; SANTOS, N.F.; COSTA, H.A.O.;FERREIRA, C.A. Produção de palhada de plantas de cobertura e rendimento do feijão em plantio direto. Pesquisa Agropecuária Brasileira, Brasília, v.41, n.6, p.943-948, 2006.

PANTANO, A.C. Semeadura de braquiária em consorciação com milho em diferentes espaçamentos na integração agricultura-pecuária em plantio direto. 2003.60 f. Dissertação (Mestrado em Agronomia/Sistemas de Produção) - Faculdade de Engenharia, Universidade Estadual Paulista, Ilha Solteira, 2003.

PARIZ, C.M.; ANDREOTTI, M.; TARSITANO, M.A.A.; BERGAMASCHINE, A.F.; BUZETTI, S.; CHIODEROLI, C.A. Desempenhos técnicos e econômicos da consorciação de milho com forrageiras dos gêneros Panicum e Brachiaria em sistema de integração lavoura-pecuária. Pesquisa Agropecuária Tropical, Goiânia, v.39, n.4, p.360-370, 2009.

PIRES, W. Manual de pastagem: formação, manejo e recuperação. Viçosa: Aprenda Fácil, 2006.

SANTOS, G.G.; SILVEIRA, P.M.; MARCHÃO, R.L.; BECQUER, T.; BALBINO, L.C.

Macrofauna edáfica associada a plantas de cobertura em plantio direto em um Latossolo Vermelho do Cerrado. Pesquisa Agropecuária Brasileira, Brasília, v.43, n.1, p.115-122, 2008.

SILVA, A.A.; JAKELAITIS, A.; FERREIRA, L.R. Manejo de plantas daninhas no Sistema Integrado Agricultura-Pecuária. In: ZAMBOLIM, L.; SILVA, A. A.; AGNES, E.L. Manejo integrado integração lavoura-pecuária. Viçosa: UFV, p.117-170, 2004.

SULC, R.M.; TRACY, B.F. Integrated crop-livestock systems in the U.S. corn belt. Agronomy Journal, Madison, v.99, n.2, p.335-345, 2007.

TIMOSSI, P.C.; DURIGAN, J.C.; LEITE, G.J. Formação de palhada por braquiárias para adoção do sistema plantio direto. Bragantia, Campinas, v.66, n.4, p.617-622, 2007. 